Research Article

\title{
Age Estimation Reports: Where do we stand?
}

\section{Sakher Al Qahtani*}

Department of Orthodontics and Pediatric Dentistry, Head of Clinical Forensic Odontology Unit, Vice President of the Arab Association of Forensic Odontologists, King Saud University, Riyadh, Saudi Arabia

\section{Abstract}

Age estimations process is not standardized worldwide. However, there is a wide agreement about the most suitable methods currently available. Up until now, the procedure of creating expert reports and to implement quality assurance in age estimation are variable.

Aim: The aim of this paper was to examine expert age estimation reports from around the world and identify the similarities and shortcomings present, which will help in providing recommendations to improve the reporting to reach standardization in expert age estimation reports.

Methods and Material: A questionnaire was developed to explore whether there is a universal consensus in writing age estimation reports. Countries participated in the survey were: Afghanistan, Australia, France, Indonesia, Italy, New Zealand, Norway, Paraguay, Saudi Arabia, Spain, Switzerland, United Arab Emirates, United Kingdom, and the United States of America. Areas investigated by the survey included: Information about the individual in question and the entity requesting the assessment, if age interval is given along with if statistics were described in the report, if population reference data are used and reported and finally if the format of the report is standardized within each country.

Results: The results of this survey suggest that there is a high degree of individual variation in age estimation reports, sometimes even within the same country. While the majority of participants report the main findings, some important information is still missing. The statistical information remains extremely varied.

Conclusion: Although a resolution is not obvious, it is hoped that this study will promote further research and discussion on reporting age estimation. International guidelines on quality assurance in age estimation reports are urgently needed. Information to be reported should be specified on an international level and the exact report format to be used could be left to the national societies.

\section{Introduction}

The process of age estimations has not been standardized. However, there is wide agreement about the most suitable methods currently available that involve the following methods [1]:

- Social interview and psychological assessment (Merton method) [2].

- Physical examination with determination of anthrometric measures (body heightand weight, constitutional type), inspection of signs of sexual maturation as well as identification of any age-relevant developmental disorders.

\section{More Information}

*Address for Correspondence: Sakher Al Qahtani, Assistant Professor, Department of Orthodontics and Pediatric Dentistry, Head of Clinical Forensic Odontology Unit, Vice President of the Arab Association of Forensic Odontologists, King Saud University, Riyadh, Saudi Arabia, Tel: +966-11-4677233; +966-505-465-027; Email: asakher@ksu.edu.sa

Submitted: 21 October 2019

Approved: 24 October 2019

Published: 25 October 2019

How to cite this article: Al Qahtani S. Age Estimation Reports: Where do we stand? J Forensic Sci Res. 2019; 3: 004-008.

DOI: dx.doi.org/10.29328/journal.jfsr.1001016

Copyright: (c) 2019 Al Qahtani S. This is an open access article distributed under the Creative Commons Attribution License, which permits unrestricted use, distribution, and reproduction in any medium, provided the original work is properly cited

Keywords: Age estimation; Expert; Report; Standardization

\section{Check for updates}


However, it is reported to have between 3 and 5 million illegal immigrants residing within its borders at any given time [4]. In addition, Saudi Arabia is the birthplace of the religion of Islam, resulting in a large number of visits most of whom are foreigners who are Muslims for the Islamic practices of Haj and Umrah. A number of these individuals stay illegally [5]. Wealth, work opportunities and its religious status make Saudi Arabia a hub for people from around the world. Although immigration is illegal [6], many people try to enter the country illegally from neighboring troubled countries and from Africa. The latest data revealed that there were 194,520 illegal immigrants in 2014, many of whom settle illegally and have children who are undocumented [7]. Not having a birth certificate, however, is not restricted to illegal immigrants. According to the UNICEF, the percentage of unregistered births is still high in the Middle East and can reach up to $50 \%$ of births [8]. Although Saudi Arabia has no statistics on unregistered births, it is presumed high, especially in rural areas.

The lack of birth certificate is problematic when it comes to children reaching school age, marriage, or involvement with law enforcement. Although Saudi Arabia has a relatively low crime rate [9], it is still faced with challenges in regard to human identification (especially age estimation) for purposes of issuing official documents, deciding if an individual is a minor or not and also when determining the age of criminal responsibility. There are several milestones for age within the legal system in Saudi Arabia that require age estimation when legal documents are absent (Table 1). The expert evaluation in an individual case should take into account whether the question(s) can be answered with a sufficiently high degree of reliability by using sound scientific methods. The examinations to be performed must be justified by a court order. Up until now, the procedure in setting up expert reports and to implement quality assurance in age estimation are variable. Summarizing age estimations, based on the used methods, should generally include the range of scatter, which have limitations [10]. Depending on what is requested, it may be necessary to assess the legally relevant age limits and/or the probability of the age given in the court order verbally. The central forensic aspect of an expert report is to give the most probable age of the examined individual and/or the degree of probability that the stated age is the actual age or that the individual's age is above the relevant penal age limit.

The ideal expert report must describe the methods and the reference studies used to estimate the age of the individual. For each examined feature, the report must indicate the most probable age and the range of scatter of the reference population [10-19]. Furthermore, it should be noted that the report should address the following: the range of tolerance may be increased by an empirical observer error; the agerelevant variations resulting from the application of the reference studies in an individual case such as deviating genetic/geographic origin, and different socioeconomic status; the degree of acceleration; the developmental disorders present (if any). The report must discuss how all these variables can affect the age estimation and, if possible, provide a quantitative assessment of any such effect should be given $[20,24]$. An important aspect in writing an expert report is understanding the question asked: "why the age is required?" Different scenarios require different approaches. For example, if the age is required to produce documents, then age estimation is sufficient. If the question is to know if the individual has reached puberty, age estimation is redundant. If the question is whether the individual has reached the age of majority, 18 years, age estimation is not appropriate and the probability is better in providing the answer. Understanding that each question has a method best suited to answer it, is important to preserve the human rights of the individual in question and also to ensure justice. The aim of this paper is to examine expert age estimation reports from around the world and identify the similarities and shortcomings present, which will help in providing recommendations to improve the reporting to reach standardization in expert age estimation reports.

Table 1: Age milestones in regard to the Saudi Arabian system.

\begin{tabular}{|c|c|}
\hline Age & Legal significance \\
\hline $\begin{array}{l}16 \text { gestation weeks [11]. } \\
\text { Using bones (Anthropological) [12]. }\end{array}$ & Fetus has to be named and given an adult burial \\
\hline $\begin{array}{c}\text { Birth (alive after birth for at least } 3 \text { days) } \\
\text { Using the neonatal line in developing teeth (Histological) } \\
\text { [13]. }\end{array}$ & If a neonate was found dead and there is a need to know if it was a live birth \\
\hline $\begin{array}{l}5 \text { years and } 9 \text { months minimum on first day of school } \\
{[1,14] .}\end{array}$ & Enter school (grade 1) \\
\hline 7 years $[1,15]$ & Age of criminal responsibility \\
\hline 9 years maximum $[1,14]$. & Enter school (grade 1) for special needs children \\
\hline 11 years and 3 months $[1,14]$. & If hasn't been to school, s/he cannot enter regular school and have to enroll in adult night school \\
\hline $\begin{array}{c}\text { Puberty } \\
\text { Using physical examination (Tanner stages) }[16,17] .\end{array}$ & Criminal responsibility in homicides \\
\hline 12 years $[1,15]$ & Can be sentenced 1 year maximum (put in rehab or social services care) \\
\hline 15 years [1]. & $\begin{array}{l}\text { - Can be sentenced as a juvenile (half the sentence of an adult maximum or } 10 \text { years maximum if the } \\
\text { crime has capital punishment except homicides) [15]. } \\
\text { - } \quad \text { Work (with special regulations) } \\
\text { - } \quad \text { Marriage [18]. }\end{array}$ \\
\hline 16 years $[1,19]$. & Age of national identification card \\
\hline 18 years $[1,15]$. & Age of majority \\
\hline
\end{tabular}




\section{Subjects and Methods}

A questionnaire was developed to explore whether there is a universal consensus in writing age estimation reports. Countries participated in the survey were: Afghanistan, Australia, France, Indonesia, Italy, New Zealand, Norway, Paraguay, Saudi Arabia, Spain, Switzerland, United Arab Emirates, United Kingdom, and the United States of America. Areas investigated by the survey included: what information on the individual in question is reported and the entity requesting the assessment, if age interval is given and if standard deviations, standard errors, age ranges, or means are described in the report, if population reference data are used and reported and finally, if the format of the report is standardized within each country. An electronic questionnaire was developed through the use of an online survey application to blindly collect information regarding age estimation reporting, preferred estimation techniques and methods used in producing a final age estimate. It consisted of 27 questions, requiring about 5 minutes to complete. To facilitate comparisons, the author aimed to format all survey questions as Yes/No responses. The questionnaire was distributed electronically to 20 Forensic Specialists from 14 countries. The responses were completely anonymous, without collection of any identifiable information, such as IP addresses or affiliations. Moreover, age estimation reports from all these countries were gathered for analysis of content and format.

\section{Results}

All 20 individuals completed the questionnaire.

The majority of participants reported the name of the individual in question in their report (90\%), all reported the sex (100\%), and nationality was reported by $85 \%$ while ancestry was reported by only $80 \%$. Age given by the individual in question was included in the report by $80 \%$ of the participants and only $65 \%$ reported if documents supplied by the individual in question were supplied/available. While $100 \%$ of participants reported the date of examination, only $85 \%$ reported the reason for the request of age estimation and $80 \%$ reported the setting of the examination. When asked if the name of the organization requesting the age estimation was included in the report, $95 \%$ of participants said yes but only $75 \%$ reported if consent was taken (Table 2).

Regarding the examination of the individual in question, only $65 \%$ of participants reported anything regarding the general state of the individual, $25 \%$ reported anything about the mental state/awareness/cognitive ability of the individual and also $25 \%$ included the height and weight of theindividual in their report (Table 3). When asked about age estimation, 90\% of participants used more than one method of age estimation with $95 \%$ of participants including the method they used in the report. All participants reported the tooth/teeth or the specific bones they assessed to do the age estimation (100\%). While all participants include the availability of radiographs for the assessment or if radiographs were taken (100\%), 95\% reported the type of the radiograph (Table 4). When asked about how the age estimation is reported, 95\% include an age interval but only $85 \%$ report a standard deviation. Moreover, only $70 \%$ mentioned population-based data references and $80 \%$ mentioned limitations of the methods used in the report. Access to a formal, national standard age estimation report form was only available to $40 \%$ of participants (Table 5). Examining age estimation reports showed different formats even within the same countries. The information reported seemed variable as well within each country and between countries. Some have tabulated forms while others use a letter format.

\section{Discussion}

The purpose of the age assessment is to provide the most likely age of an individual and reporting it to the authority

Table 2: Questions regarding the information of the individual whose age is disputed and the entity that requested the age assessment.

\begin{tabular}{|c|c|c|c|}
\hline Question & Yes & No Total \\
\hline Do you include the name of the person in question? & 18 & 2 & 20 \\
\hline Do you include the gender of the person in question? & 20 & 0 & 20 \\
\hline Do you include the nationality of the person in question? & 17 & 3 & 20 \\
\hline Do you include the ancestry of the person in question? & 16 & 4 & 20 \\
\hline $\begin{array}{c}\text { Do you include the given age of the person in question recorder } \\
\text { previously (in other documents or by their own statement)? }\end{array}$ & 16 & 4 & 20 \\
\hline Do you include the date of the examination? & 20 & 0 & 20 \\
\hline \begin{tabular}{c} 
Do you mention the reason why the age estimation was requested? \\
\hline Do you include the setting of the examination?
\end{tabular} & 17 & 3 & 20 \\
\hline Do you mention the organization that requested the report? & 19 & 1 & 20 \\
\hline $\begin{array}{c}\text { Do you mention/list available identification documentation that the } \\
\text { person in question has? }\end{array}$ & 13 & 7 & 20 \\
\hline $\begin{array}{c}\text { Do you mention if consent was taken from the person in question or } \\
\text { their legal representative? }\end{array}$ & 15 & 5 & 20 \\
\hline
\end{tabular}

Table 3: Questions regarding the examination of the individual who's age is disputed. $\begin{array}{cc}\text { Question } & \text { Yes No Total }\end{array}$ \begin{tabular}{|l|l|l|l|l|}
\hline Do you mention anything regarding the general state of the person & 13 & 7 & 20
\end{tabular} in question?

\begin{tabular}{|l|l|l|l|l|l}
13 & 7 & 20 \\
\hline
\end{tabular}

\begin{tabular}{|l|l|l|l|}
\hline $\begin{array}{c}\text { Do you mention anything regarding the mental state/awareness/ } \\
\text { cognitive ability of the person in question? }\end{array}$ & 5 & 15 & 20
\end{tabular}

\begin{tabular}{|l|l|l|l|}
\hline Do you include the height/weight of the person in question? & 5 & 15 & 20
\end{tabular}

Table 4: Questions regarding the age assessment process.

\begin{tabular}{|c|c|c|c|}
\hline Question & Yes & No & Total \\
\hline Do you include the method used for age estimation? & 19 & 1 & 20 \\
\hline Do you use more than one method to do age estimation? & 18 & 2 & 20 \\
\hline $\begin{array}{c}\text { Do you mention the tooth/teeth (in case of dental age estimation) } \\
\text { or bones (in case of bone age estimation) that were assessed? }\end{array}$ & 20 & 0 & 20 \\
\hline Do you mention if Radiographs were taken/available? & 20 & 0 & 20 \\
\hline Do you mention the type of Radiographs taken/available? & 19 & 1 & 20 \\
\hline
\end{tabular}

Table 5: Questions regarding the age assessment results and the written report.

\begin{tabular}{|c|c|c|c|}
\hline Question & Yes & No & Total \\
\hline Do you report an age interval? & 19 & 1 & 20 \\
\hline Do you report a standard deviation? & 17 & 3 & 20 \\
\hline $\begin{array}{c}\text { Do you mention population-based data references? } \\
\text { Do you mention limitations that exist? (with examination or } \\
\text { method used) }\end{array}$ & 14 & 6 & 20 \\
\hline $\begin{array}{c}\text { Do you have access to a formal, national standard age } \\
\text { estimation report form? }\end{array}$ & 8 & 12 & 20 \\
\hline \begin{tabular}{c} 
Derme \\
\hline
\end{tabular}
\end{tabular}


that requested it. Reporting age estimation can significantly impact an individual future. The weight of the age estimation can be affected by the way it is written in the official report. The focus of this study is on the reporting of age estimation, not the age estimation techniques. The major finding is the lack of standardized age estimation report format and the inconsistency in the information provided, which may have a negative effect on the individual in question. Knowing why the age is disputed is crucial for writing the report as the estimated age has to be in the best interest of the individual in question (within the age interval) [25]. In cases where the court is requesting an age assessment, they might ask explicitly for what they want to know. However, other civil organizations may not know what to ask for. Taking the given age and the estimated age into consideration could be of great value. Background information and the general state (including the mental/cognitive abilities) of the individual in question are very important because age estimation has to be a holistic approach [25], including psychological assessment, physical and radiographic examination. In most scenarios, these factors are not taken into consideration in the assessment of the age, or at least not included in the report. Knowing these factors is important to assess if the methods are appropriate in relation to the individual; whether they have an effect on development, especially if there are any pathologic factors. Including the general/mental state in the report shows that these factors were checked and assessed.

Referencing the methods used in the report is important. Although following the methodology of age assessment is clear: identifying a developmental stage or applying a formula, there is no requirement of stating a standard deviation or confidence interval. The report should never give any wrong information, especially when it comes to statistics. However, the figures for the distribution of the data must only be taken as indicative for the real variation in the actual population. The age assessment report should include the likelihood of an official age, if it exists, and the likelihood of an alternative age if it exists. Therefore, instead of just including the standard deviation, the likelihood of these two ages and if one can be excluded, should be expressed. The conclusion of the report, however, should end with a complete assessment of the most likely chronological age. Assessing the age of majority, 18 years, should be reported in a different way than the age estimation required to issue documents. Assessment in these cases, like the likelihood that the asylum seeker is below or above 18 years of age, should be done to exclude that they are below the age of 18 years as well as the likelihood or possible exclusion of their given age.

The recommendations of the International Organization of Forensic Odonto-Stomatology (IOFOS) regarding quality assurance should be followed and a statement of that should be included in the report [26]. Two assessors should cooperate in order to perform the age assessment. The second assessor should read the report and suggest corrections and agree to the exact conclusion before signing the report. The results of this survey suggest that there is a high degree of individual variation in age estimation reports, sometimes even within the same country. While the majority of participants report the main findings, some important information is still missing. The statistical information and how the age ranges, from multiple methods, are combined into a final age estimate, remains extremely varied and at times statistically invalid. Many still rely on experience and expertise when determining a final age estimate, in many cases to narrow the broad range provided by statistical information, such as confidence intervals. While experience is no doubt an important factor, this introduces a certain amount of subjectivity.

\section{Conclusion}

The issues presented by this study results are complex. Although a resolution is not obvious, it is hoped that this study will promote further research and discussion on reporting age estimation. Many forensic specialists acknowledge these issues and this survey validates those concerns. There are currently no standards on what statistical information should be reported within the body of the report in the literature, what statistical information practitioners should use from the studies or consensus on how to combine the information from multiple age indicators into the final estimate of age report to officials. International guidelines on quality assurance in age estimation reports are urgently needed. Information to be reported should be specified on an international level and the exact report format to be used should be created by consensus of experts from national organizations.

\section{References}

1. Schmeling A, Grundmann C, Fuhrmann A. Criteria for age estimation in living individuals. Int J Legal Med. 2008; 122: 457-460. PubMed: https://www.ncbi.nlm.nih.gov/pubmed/18548266

2. Merton RK, Fiske M, Kenddl PL. The Focused Interview. Glencoe, Illinois.

3. Saudi Arabia. General Census of Population and housing, cdosa. 2010

4. Al Qahtani S, AI Shahrani Y, AI Qahtani A. Reality of forensic odontology in Saudi Arabia. Revista Brasileira de Odontologia Legal. 2017; 4.

5. Saudi Arabia. General Directorate of Public Security, Ministry of Interior. 2014.

6. Saudi Arabia. Immigration Regulations, dgo. Passports. 2014.

7. Saudi Arabia. General Census of Omrah, TMoH. 2014

8. UNICEF Data: Monitoring the Situation of Children and Women. Birth Registration report. 2016.

9. Saudi Arabia. Crime Rate in the Kingdom of Saudi Arabia, Ministry of Interior. 2015.

10. Rösing FW. Forensic Age Diagnosis: Statistics, Working Rules and Presentation. In: Oehmichen M, Geserick G (eds) Osteological Identification (Research in Legal Medicine). Schmidt-Roemhild, Luebeck. 2000; 263-275. 
11. Zarabozo JDM. The Forty Hadith of al-Nawawi: with an Introduction by Prof. Jaafar Sheikh Idris Al Basheer. 2009.

12. HadlockFP, Deter RL, Harrist RB, ParkSK. Estimating fetal age: computerassisted analysis of multiple fetal growth parameters. Radiology. 1984. 152: 497-501.

PubMed: https://www.ncbi.nlm.nih.gov/pubmed/6739822

13. Janardhanan M, Umadethan B, Biniraj K, Kumar RV, Rakesh S. Neonatal line as a linear evidence of live birth: Estimation of postnatal survival of a new born from primary tooth germs. J Forensic Dent Sci. 2013; 1: 8-13.

PubMed: https://www.ncbi.nlm.nih.gov/pubmed/22022132

14. Saudi Arabia. Admission Registration Guide. Ministry of Education. 2019.

15. Saudi Arabia. Regulations of the Minors. 2018.

16. Marshall WA, Tanner JM. Variations in the pattern of pubertal changes in boys. Arch Dis Child. 1970; 45: 13-23.

PubMed: https://www.ncbi.nlm.nih.gov/pubmed/5440182

17. Marshall WA, Tanner JM. Variations in pattern of pubertal changes in girls. Arch Dis Child. 1969; 44: 291-303.

PubMed: https://www.ncbi.nlm.nih.gov/pubmed/5785179

18. Routers. Is Saudi Arabia on the road to ending child marriage? 2019.

19. Saudi Arabia. National ID, Ministry of Interior. 2019.

20. Cameriere R, Flores-Mir C, Mauricio F, Ferrante L. Effects of Nutrition on Timing of Mineralization in Teeth in a Peruvian sample by the Cameriere and Demirjian methods. Ann Hum Biol. 2007; 34: 547-556. PubMed: https://www.ncbi.nlm.nih.gov/pubmed/17786590

21. Meijerman L, Maat GJR, Schulz R, Schmeling A. Variables affecting the probability of complete fusion of the medial clavicular epiphysis. Int $\mathrm{J}$ Leg Med. 2007; 121: 463-468.

PubMed: https://www.ncbi.nlm.nih.gov/pubmed/17909834

22. Olze A, Schmeling $A$, Taniguchi $M$, Maeda $H$, Van Niekerk $P$, et al. Forensic age estimation in living subjects: the ethnic factor in wisdom tooth mineralization. Int J Leg Med. 2004; 118: 170-173. PubMed: https://www.ncbi.nlm.nih.gov/pubmed/14767777

23. Schmeling A, Reisinger W, Loreck D, Vendura K, Markus W, et al. Effects of ethnicity on skeletal maturation: consequences for forensic age estimations. Int J Leg Med. 2000; 13: 252-258.

PubMed: https://www.ncbi.nlm.nih.gov/pubmed/11009058

24. Schmeling A, Schulz R, Danner B, Rösing F. The impact of economic progress and modernization in medicine on the ossification of hand and wrist. Int J Leg Med. 2006; 120: 121-126.

PubMed: https://www.ncbi.nlm.nih.gov/pubmed/16012824

25. Unhcr. Guidelines on assessing and determining the best interests of the child. The UN Refugee Agency. 2018.

26. Solheim T, Vonen A. Dental age estimation, quality assurance and age estimation of asylum seekers in Norway. Forensic Science International. 2006; 159: 56-60.

PubMed: https://www.ncbi.nlm.nih.gov/pubmed/16542802 